\title{
MORPHOMETRIC MEASUREMENTS OF SEGMENTS IN DRY HUMERUS
}

\author{
Pranoti Sinha1 ${ }^{1}$ Karma Lakhi Bhutia², Binod K. Tamang ${ }^{3}$
}

${ }^{1}$ Associate Professor, Department of Anatomy, Sikkim Manipal Institute of Medical Sciences, Tadong, Gangtok, Sikkim.

${ }_{2}^{2}$ Lecturer, Department of Anatomy, Sikkim Manipal Institute of Medical Sciences, Tadong, Gangtok, Sikkim.

3Professor, Department of Anatomy, Sikkim Manipal Institute of Medical Sciences, Tadong, Gangtok, Sikkim.

\section{ABSTRACT}

\section{BACKGROUND}

The humerus which being the long bone in the arm presents with two expanded ends- upper end and lower end. The present study was conducted to study the different morphometric analysis of segments of humerus. Estimating the stature from long bones plays an important role for Anatomist, Anthropologist and Forensic expert to identify unknown body parts of bodies or skeletal remains. It is also important for surgeons to identify fractures of proximal and distal end of humerus for the reconstructive surgery of fracture of humerus.

The objective of this study was to study the morphometry of humerus and compare the findings with previous studies.

\section{MATERIALS AND METHODS}

A descriptive study was conducted on 49 human dry humerus, out of which 25 were of left side and 24 were of right side. Ten different parameters were measured to study the morphometry of humerus by using digital caliper, measuring tape, graph paper, cardboard and measuring scale.

\section{RESULTS}

In our study, we observed the mean value of the total humerus to the $283.36, \pm 22.48 \mathrm{~mm}$ and $290.17, \pm 18.67 \mathrm{~mm}$ on the left and right side respectively. Maximum transverse diameter of head $38.18, \pm 4.78 \mathrm{~mm}$ on the left side and $35.85, \pm 5.09 \mathrm{~mm}$ on the right side. The maximum vertical diameter was $40.01, \pm 4.39 \mathrm{~mm}$ on left and right side respectively. The surface area of the head of the humerus was $22.23, \pm 3.77 \mathrm{~mm}$ on the left side and $22.17, \pm 4.09 \mathrm{~mm}$ on the right side.

\section{CONCLUSION}

The knowledge of morphometric measurement of segments of humerus is important for anatomist. Forensic experts and archaeologist to define the identity of a skeleton as well as the stature. It also helps the surgeons in various surgeries of humerus for implantation. In this study, there was no significant difference with other authors except for surface area of the head of the humerus.

\section{KEYWORDS}

Humerus, Anthropometry, Digital Caliper, Morphometry.

HOW TO CITE THIS ARTICLE: Sinha P, Bhutia KL, Tamang BK. Morphometric measurements of segments in dry humerus. J. Evolution Med. Dent. Sci. 2017;6(67):4819-4822, DOI: 10.14260/Jemds/2017/1045

\section{BACKGROUND}

The humerus or the arm bone being the longest and strongest bone of the upper limb and presents with two expanded ends- upper and lower ends and an intervening shaft which is cylindrical in shape. To know about the length, size and shape of the humerus is very important for anatomists and anthropologists. Estimation of stature from bones plays an important role in identifying unknown bodies, parts of bodies or skeletal remains in Forensic science. Knowing the mean length and weight of humerus segments is very important for anatomist and forensic experts and helps the investigator to define the identity of a skeleton. It is also important for the surgeons to identify the proximal and distal fracture of the humerus.

Financial or Other, Competing Interest: None.

Submission 17-07-2017, Peer Review 10-08-2017,

Acceptance 16-08-2017, Published 21-08-2017.

Corresponding Author:

Dr. Karma Lakhi Bhutia,

Lecturer, Department of Anatomy,

Sikkim Manipal Institute of Medical Sciences,

$5^{\text {th }}$ Mile, Tadong, Gangtok-737102, Sikkim.

E-mail: klbutia@gmail.com

DOI: $10.14260 /$ jemds $/ 2017 / 1045$

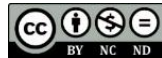

Mullar first measured five segments of the humerus by using the margins of articular surfaces and key points of muscle attachment. These findings are very useful to determining the humerus segment.(1) In many situations the full length of the long bone may not be available but only segment of bones may be available, in that case some methods can be used as per studies of Wright.(2) These measurements indicate the characteristic morphological features of humerus segment in Indian population and provides data for various implants in reconstruction of various humerus fractures. The present study is conducted for morphometric analysis of segments of humerus.

\section{MATERIALS AND METHODS}

The study design is a descriptive study and in the present study 49 numbers of dry humerii were collected from the Department of Anatomy of Sikkim, Manipal Institute of Medical Sciences in Gangtok. Ten different parameters of humerus were measured to study the morphometry of the humerus by using digital caliper, measuring tape, graph paper, card board and measuring scale.

a. Maximum length of humerus: It measures the distance between the highest point of the head of the humerus to the most distal point of the trochlea. 
b. Maximum transverse diameter of the head: It measures the straight distance between the most lateral points on articular surface of the head.

c. Maximum vertical diameter of the head: It measures the straight distance between the highest and lowest points on the articular surfaces, taken at right angle to the transverse diameter.

d. Girth of the head: It measures the circumference of the head along its articular surface.

e. Breadth of the trochlea: It measures the breadth between the midpoint of the lateral margin of the trochlea and midpoint of lateral margin of capitulum. f. Maximum diameter of the shaft.

g. Minimum diameter of the shaft.

h. Anterior-posterior diameter of trochlea.

i. Distance between medial and lateral epicondyle.

j. Surface area of the head of the humerus.

All the parameters were recorded and analysed statistically by using SPSS 16 . The mean and standard deviation was calculated.

\begin{tabular}{|c|c|c|c|c|c|}
\hline Side & Length & MTDH & MVDH & GOHead & BOTROCHLEA \\
\hline Left Mean & 283.36 & 38.18 & 40.93 & 124.84 & 25.82 \\
N & 25 & 25 & 25 & 25 & 25 \\
STD DEV & \pm 22.48 & \pm 4.786 & \pm 5.14 & \pm 11.75 & \pm 2.76 \\
\hline Right Mean & 290.17 & 38.85 & 42.01 & 136.58 & 26.08 \\
N & 24 & 24 & 24 & 24 & \pm 2.61 \\
STD DEV & \pm 18.67 & \pm 5.09 & 41.46 & 130.59 & 25.95 \\
\hline Total & 286.69 & 38.51 & 49 & 49 & 49 \\
Mean & 49 & 49 & \pm 4.77 & \pm 33.86 & \pm 2.66 \\
N & \pm 20.78 & \pm 4.90 & 0.619 & 1.488 & 0.112 \\
STD DEV & 1.323 & 0.225 & 0.436 & 0.229 & 0.739 \\
\hline F-Value & 0.256 & 0.637 &
\end{tabular}

\begin{tabular}{|c|c|c|c|c|c|}
\hline SIDE & MxDOS & MnDOS & APDOT & DBMAL & SURAH \\
\hline Left Mean & 31.73 & 26.17 & 27.43 & 56.11 & 22.23 \\
\hline $\mathrm{N}$ & 25 & 25 & 25 & 25 & 25 \\
\hline STD DEV & \pm 31.3 & \pm 1.87 & \pm 1.97 & \pm 5.41 & \pm 3.77 \\
\hline Right Mean & 31.01 & 25.52 & 27.58 & 57.64 & 22.17 \\
\hline $\mathrm{N}$ & 24 & 24 & 24 & 24 & 24 \\
\hline STD DEV & \pm 3.42 & \pm 2.33 & \pm 1.73 & \pm 5.33 & \pm 4.09 \\
\hline Total Mean & 31.38 & 25.85 & 27.51 & 56.86 & 22.20 \\
\hline $\mathrm{N}$ & 49 & 49 & 49 & 49 & 49 \\
\hline STD DEV & \pm 3.26 & \pm 2.11 & \pm 1.84 & \pm 5.37 & \pm 3.88 \\
\hline F-Value & 0.585 & 1.137 & 0.082 & 0.999 & 0.003 \\
\hline P-Value & 0.448 & 0.292 & 0.776 & 0.323 & 0.955 \\
\hline
\end{tabular}

(MxDOS- Maximum Diameter of Shaft, MnDoS- Minimum Diameter of Shaft, APDOT- Anterior Posterior Diameter of
Trochlea, DBMAL- Distance Between Medial and Lateral Epicondyle, SURAH- Surface Area of Head of Humerus) \pm

\begin{tabular}{|c|c|c|c|c|c|c|c|c|c|}
\hline $\begin{array}{l}\text { Sl. } \\
\text { No }\end{array}$ & Authors & Year & Length & MVDH & MTDH & GoHead & BoTrochlea & APDOT & MxDoS \\
\hline 1. & S.D A K Man & 2005 & $\begin{array}{r}\text { L 304.8, } \pm 1.8 \\
\text { R 307.10, } \pm 2.1\end{array}$ & $\begin{array}{l}40.9, \pm 3.9 \\
41.0, \pm 5.1 \\
\end{array}$ & - & - & $\begin{array}{l}40.6, \pm 3.3 \\
39.7, \pm 3.4 \\
\end{array}$ & - & - \\
\hline 2. & S.D Desai et al & 2012 & $\begin{array}{r}\text { L } 289.4, \pm 21.8 \\
\text { R } 292.3, \pm 22.9\end{array}$ & 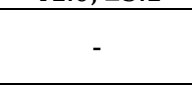 & - & - & (5) & - & - \\
\hline 3. & Niraj $\mathrm{P}$ et al & 2013 & $\begin{array}{l}\text { L } 307.27, \pm 16.13 \\
\text { R } 308.58, \pm 19.17\end{array}$ & - & - & - & - & - & - \\
\hline 4. & $\begin{array}{c}\text { Lokanadham } \\
\text { et al }\end{array}$ & 2013 & \begin{tabular}{|c|} 
M 310.97, \pm 0.15 \\
F 280.65, \pm 0.15 \\
\end{tabular} & $\begin{array}{l}30.27, \pm 0.03 \\
20.96, \pm 0.04\end{array}$ & \begin{tabular}{|l|}
$40.37, \pm 0.42$ \\
$30.49, \pm 0.04$ \\
\end{tabular} & $\begin{array}{l}120.96, \pm 0.09 \\
110.52, \pm 0.12\end{array}$ & \begin{tabular}{|l|}
$20.34, \pm 0.022$ \\
$20.09, \pm 0.034$
\end{tabular} & - & $\begin{array}{c}40.39, \pm 0.42 \\
30.492, \pm 0.04\end{array}$ \\
\hline 5. & Ashiyani et al & 2016 & $\begin{array}{l}\text { L 300.32, } \pm 1.58 \\
\text { R 300.39, } \pm 1.66 \\
\end{array}$ & 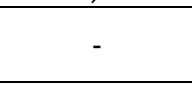 & t & 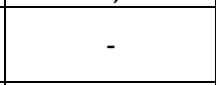 & t & $\begin{array}{l}10.45, \pm 0.15 \\
10.15, \pm 0.14\end{array}$ & - \\
\hline 6. & Pranoti et al & 2017 & $\begin{array}{l}\text { L 283.36, } \pm 22.48 \\
\text { R 290.17, } \pm 18.67\end{array}$ & $\begin{array}{l}40.93, \pm 5.14 \\
42.01, \pm 4.39 \\
\end{array}$ & \begin{tabular}{|l|}
$38.18, \pm 4.79$ \\
$38.85, \pm 5.09$
\end{tabular} & $\begin{array}{l}124.84, \pm 11.75 \\
136.58, \pm 46.64\end{array}$ & \begin{tabular}{|l|}
$25.82, \pm 1.97$ \\
$26.08, \pm 2.61$ \\
\end{tabular} & \begin{tabular}{|l|}
$27.43, \pm 1.97$ \\
$27.58, \pm 1.73$ \\
\end{tabular} & \begin{tabular}{|l|}
$31.73, \pm 31.3$ \\
$31.01, \pm 3.42$ \\
\end{tabular} \\
\hline
\end{tabular}



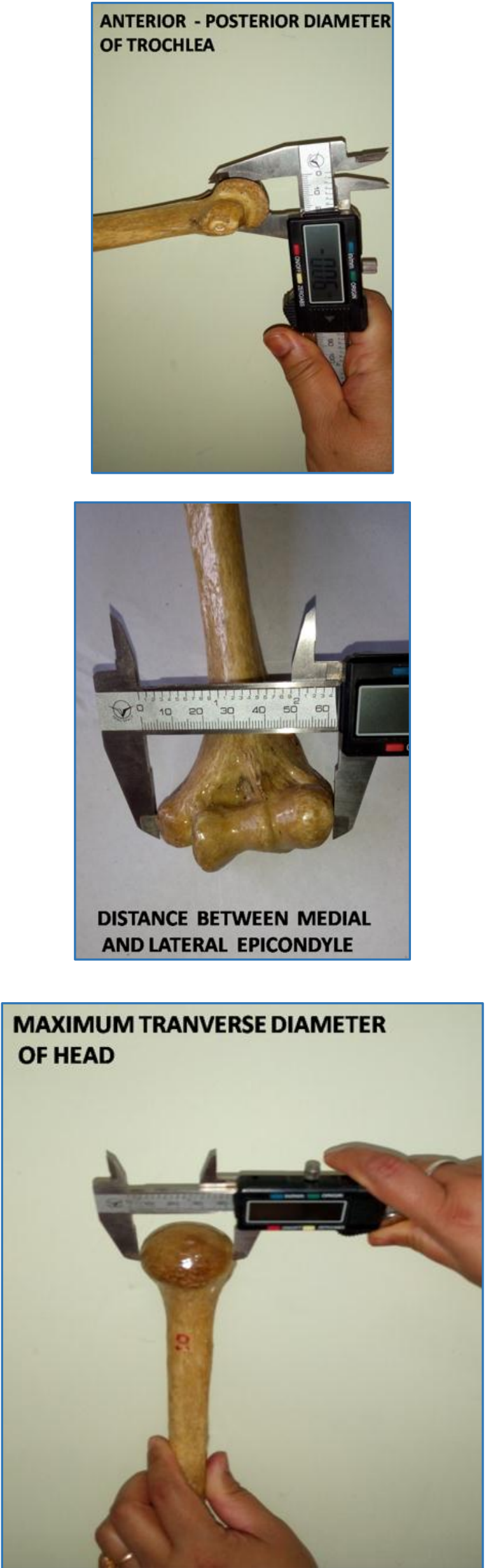

\section{MAXIMUM VERTICAL DIAMETER OF THE} HEAD
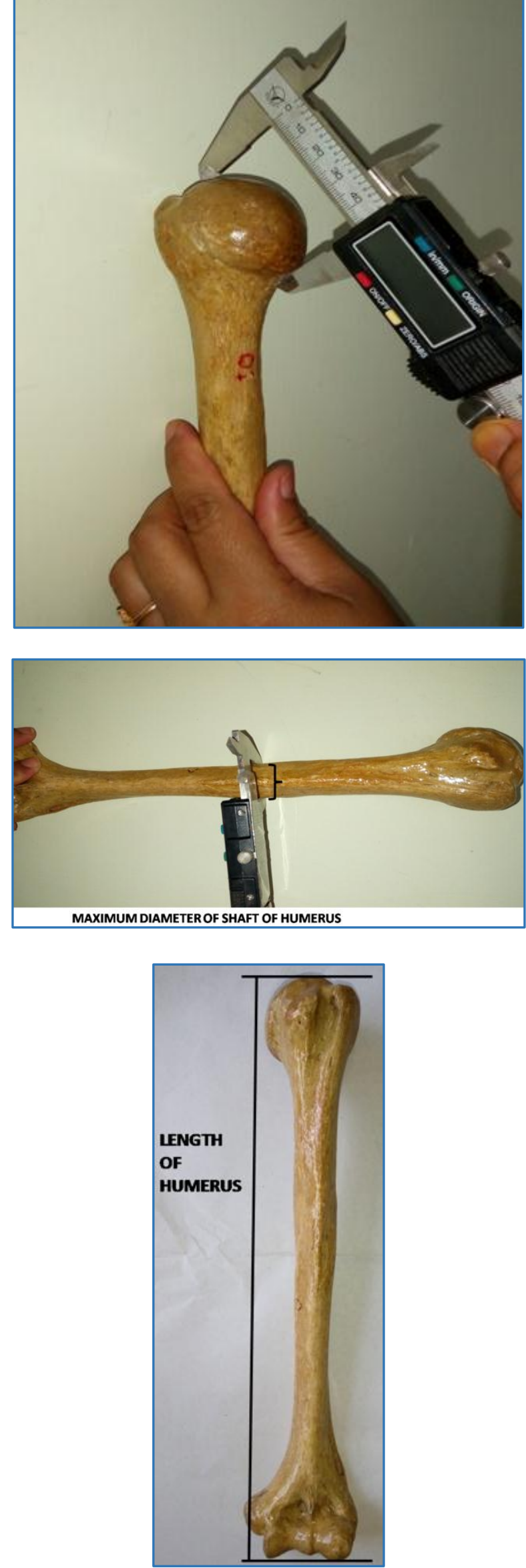


\section{RESULTS}

The present study was conducted in 49 humerus (out of which 25 are of left side and 24 are of right side) to determine the different parameters of the humerus.

The maximum length of the humerus was $283.36, \pm 22.48$ $\mathrm{mm}$ on left side and $290.17, \pm 18.67 \mathrm{~mm}$ on the right side. Maximum transverse diameter was $38.18, \pm 4.78 \mathrm{~mm}$ on left side and $35.85, \pm 5.09 \mathrm{~mm}$ on the right side. Maximum vertical diameter of head was $40.93, \pm 5.14 \mathrm{~mm}$ on left side $42.01, \pm 4.39 \mathrm{~mm}$ on the right side. The maximum diameter of girth of head was $124.84, \pm 11.75 \mathrm{~mm}$ on the left side and $136.58, \pm 46.64 \mathrm{~mm}$ on the right side. The breadth of trochlear on the left side was $25.82, \pm 2.76 \mathrm{~mm}$ and $26.08, \pm$ $2.61 \mathrm{~mm}$ on the right side.

The maximum diameter of shaft of humerus was $31.73, \pm$ $31.3 \mathrm{~mm}$ on left side and $31.01, \pm 3.42 \mathrm{~mm}$ on the right side. The minimum diameter of shaft was $26.17, \pm 1.87$ on the left side and $25.52, \pm 2.33 \mathrm{~mm}$ on the right side. Antero-posterior diameter of trochlea was $27.43, \pm 1.97 \mathrm{~mm}$ on left side and $27.58, \pm 1.73 \mathrm{~mm}$ on the right side. The distance between the medial and lateral condyle of humerus on the left side was $56.11, \pm 5.41 \mathrm{~mm}$ and $57.64, \pm 5.33 \mathrm{~mm}$ on the right side. The surface area of head of the humerus was $22.23, \pm 3.77 \mathrm{~mm}$ on the left side and 22.17, $\pm 4.09 \mathrm{~mm}$ on the right side (Table 1 ).

\section{DISCUSSION}

The humerus being the longest and strongest bone of the upper limb and is very important to identify the humeral length by segmental measurements which is applicable for anatomist, anthropologist and forensic specialist in various studies. It is also essential for the surgeons in fractures of upper and distal end of the humerus. Thus knowing these segment measurements, which are defined is very helpful for determining the humerus length.(3)

In this study, the mean values of the total length of the humerus was identified as 283.36, $\pm 22.48 \mathrm{~mm}$ and 290.17, \pm $18.67 \mathrm{~mm}$ on left and right humerus respectively. In comparison to the findings of this study, the total mean values of the total humerus length was $283.36, \pm 22.48 \mathrm{~mm}$ and $290.17, \pm 18.67 \mathrm{~mm}$ on the left and right respectively. The results were similar with the studies done by S D Desai et al $(4,5)$ (Table 3).

The maximum vertical diameter of head of the humerus was $40.39, \pm 5.14 \mathrm{~mm}$ on the left side and $42.01, \pm 4.39 \mathrm{~mm}$ which were similar with the measurements of S D Akmann et al(6) (Table 3).

In a study done by Lokanadham et al, the maximum transverse diameter of head of humerus was $40.37, \pm 0.420$ $\mathrm{mm}$ in males and 30.492, $\pm 0.042 \mathrm{~mm}$ in females, whereas in this study the measurement was $38.18, \pm 4.786 \mathrm{~mm}$ and $38.85, \pm 5.09$ on the left and right side respectively.

The girth of the head in this study was $124.84, \pm 11.75$ $\mathrm{mm}$ on the left side and $136.58, \pm 46.64 \mathrm{~mm}$ on the right side which are similar with the study done by Lokandham et al.(7)

The breadth of the trochlea in this study was $25.82, \pm 2.76$ $\mathrm{mm}$ and $26.08, \pm 26.10 \mathrm{~mm}$ on the left and the right side, whereas study done by Lokandham et al were 20.34, \pm 0.022 $\mathrm{mm}$ in males and 20.09, $\pm 0.034 \mathrm{~mm}$ in females(7) (Table 1).

The antero-posterior diameter of the trochlea in this study was $27.43, \pm 1.97 \mathrm{~mm}$ on the left side and $27.58, \pm 1.73$ on the right side which was different from the study done by Ashiyani et al which were $10.45, \pm 0.15 \mathrm{~mm}$ on the right side and $10.45, \pm 0.17 \mathrm{~mm}$ on the left side. ${ }^{8}$ The maximum diameter of the shaft of the humerus in this study was 31.73 , $\pm 31.3 \mathrm{~mm}$ on the left side and $30.01, \pm 3.42 \mathrm{~mm}$ on the right side, whereas study done by Lokanadham et al the measurements were 40.378, $\pm 0.420 \mathrm{~mm}$ in males and $30.492, \pm 0.042 \mathrm{~mm}$ in females.(7)

The final measurement done in this study was surface area of the head of humerus. The readings were 22.23, \pm 3.77 $\mathrm{mm}$ on the left side and $22.17, \pm 4.09 \mathrm{~mm}$ on the right side. No previous data were found in relation with the surface area of the head (Table 2).

\section{CONCLUSION}

The knowledge of morphometric measurements of segments of humerus is important for Anatomist, Forensic Science and Archaeologist to identify the relationship between length of long bones and height of living as well as unknown bone fragments which may be influenced by different factors such as ethnicity, age, sex, race and culture. It is also helpful for the clinician to treat the proximal and distal fracture of humerus and also help the orthopaedic surgeon in various reconstructive surgery of humerus for implantation.

In this study, there was no significant difference with the other authors except for the surface area of the head of the humerus.

\section{REFERENCES}

[1] Wright LE, Vasquez MA. Estimation of the length of incomplete long bones: forensic standards from Guatemala. Am J Phys Anthropol 2003;120(3):233-51.

[2] Nath S, Badkur P. Reconstruction of stature from long bone lengths. Int J Osteoachaeol 2001;1:109-14.

[3] Munoz JI, Linares-Iglesias M, Suarez-Penaranda JM, et al. Stature estimation from radiographically determined long bone length in a Spanish population sample. J Forensic Sci 2001;46(2):363-6.

[4] Desai SD, Shaik HS. A morphometric study of humerus segmentsj pharma. Sci \& Res 2012;4(10):1943-5.

[5] Niraj P, Dangol PMS, Ranjit N. Measurement of length and weight on non-articulated adult humerus in Nepalese corpses. Journal of Kathmandu Medical College 2013;2(3):25-7.

[6] Akman SD, Karakas PM, Bozkir G. The morphometric measurements of humerus segments. Turkish Journal of Medical Sciences 2006;36:81-5.

[7] Lokanadham S, Khaleel N, Raj PA, et al. Morphometric analysis of Humerus bone in Indian population. Sch J App Med Sci 2013;1(4):288-90.

[8] Ashiyani ZA, Solanki S, Mehta CD. The morphometric measurement of segments of humerus. J Res Med Den Sci 2016;4(1):38-40. 